\title{
Sinusoidal AC Voltage Regulator Using PWM Technique
}

\author{
A.El-Sabbe \\ Department of Electrical Engineering, Faculty of Engineering, \\ Menoufia University, Shebin El-Kom, Egypt.
}

\begin{abstract}
:
This paper proposes an $\mathrm{AC}$ voltage regulator for resistive loads using the PWM technique. The load voltage can be controlled using one switching element( MOSFET) and three limb magnetic circuit.

The suggested regulator gives smooth variation of the load voltage and nearly sinusoidal current at the supply terminals with minimum harmonics. The power factor at the supply terminals is nearly unity over the control range of the load voltage. Equivalent circuit of the regulator is proposed. The computed results are compared with those obtained experimentally using a test model, where good agreement is achieved.
\end{abstract}

\section{1-List of symbols:}

$\mathbf{R}_{1}, \mathbf{R}_{2}, \mathbf{R}_{3}, \mathbf{R}_{4}$ coil resistance's from 1 to 4 respectively,

$\mathrm{L}_{1}, \mathrm{~L}_{2}, \mathrm{~L}_{3}, \mathrm{~L}_{4}$ coil leakage inductance's from 1 to 4 respectively,

$R_{a}, R_{b}, R_{c} \quad$ equivalent iron losses resistance's of limb a, b, $c$ respectively,

$\mathrm{L}_{\mathrm{a}}, \mathrm{L}_{\mathrm{b}}, \mathrm{L}_{\mathrm{c}} \quad$ magnetizing inductance's of limb $\mathrm{a}, \mathrm{b}, \mathrm{c}$ respectively,

$i_{a}, i_{b}, i_{c}$ magnetizing current's of limb a, $b$, c respectively,

$\mathrm{E}_{\mathrm{a}}, \mathrm{E}_{\mathrm{b}}, \mathrm{E}_{\mathrm{c}}$

$\mathrm{i}_{\mathrm{s}}, \mathrm{i}_{\mathrm{l}}, \mathrm{i}_{\mathrm{sw}}, \mathrm{i}_{\mathrm{s}}$ $\mathbf{R}_{1}$ induced E.M.F's of limb a, b, c respectively, supply, load, switch and capacitor current respectively,

2-Introduction:

AC voltage controllers have been widely used to obtain variable ac voltage from a fixed voltage ac source. These controllers should respond to the requirements of the load rapidly and smoothly, preferably without causing noticeable distortion to the voltage waveform.

The moving- coil voltage regulator $[1,2,3]$, provides smooth voltage regulation at the output terminals without any distortion. However, this regulator is cumbersome and costly. Also, a mechanical system is required for the moving coil. In reference[4], replacement of the moving coil by two multitapped windings such that the effect of mechanical movement can be done using triac switches between the taps. In that way, the regulator becomes static and the voltage is regulated in a stepped manner.

A controlled thyristor voltage regulator with sinusoidal output is introduced in reference [5]. The principle of operation of the moving-coil regulator is exploited, but a three limb magnetic circuit without air-gap is employed. This controller gives a sinusoidal output voltage. However the control circuit is complex, the output voltage changed in stepped manner and the sequence of switches operation will affect in the output voltage

Manuscript received from Dr. A. El- Sabbe

Accepted on : $7 / 4 / 2001$

Engineering Research Journal Vol 24, No 3, 2001 Minufiya University, Faculty Of Engineering , Shebien El-Kom , Egypt , ISSN 1110-1180 
The phase angle control of ac voltage controllers is extensively employed in many applications such as industrial heating, lighting control and for starting and voltage control of induction motors. This technique offers the advantages of simplicity and ability of controlling large amount of power economically.

However, a delayed firing angle causes discontinuity and significant harmonics in load current, and lagging power factor. This occurs also, at the ac side even though the load is completely resistive [6]. These problems can be solved by introducing more advanced control techniques in ac chopper such as symmetrical angle control, asymmetrical angle control and modification of the power circuit with freewheeling path [7-11].

This paper introduces an ac voltage controller using PWM technique with one MOSFET and three limb magnetic circuit. The proposed system gives nearly sinusoidal output voltage, minimum distortion at the supply terminals and higher power factor over the control range. The capacitance at the load terminals is used to improve the supply quality. A prototype for the proposed system with the driving circuit of MOSFET are built and tested in the laboratory. In order to compute the system performance, the equivalent circuit is developed and examined by comparing the simulation and experimental results.

\section{3-Description of the proposed system:}

The power circuit of an ac voltage regulator with PWM technique is shown in Fig.[1]. The three limbs of the magnetic circuit are of the same crosssectional area, the coils in the same limb are separated. Coilsl and 2 are connected in series to the supply, such that the flux in the center limb is the sum of the flux in the two outer limbs as coils 3 and 4 are opened. The four coils are designed with equal turns and with suitable core flux level as the supply voltage is applied to any coil.

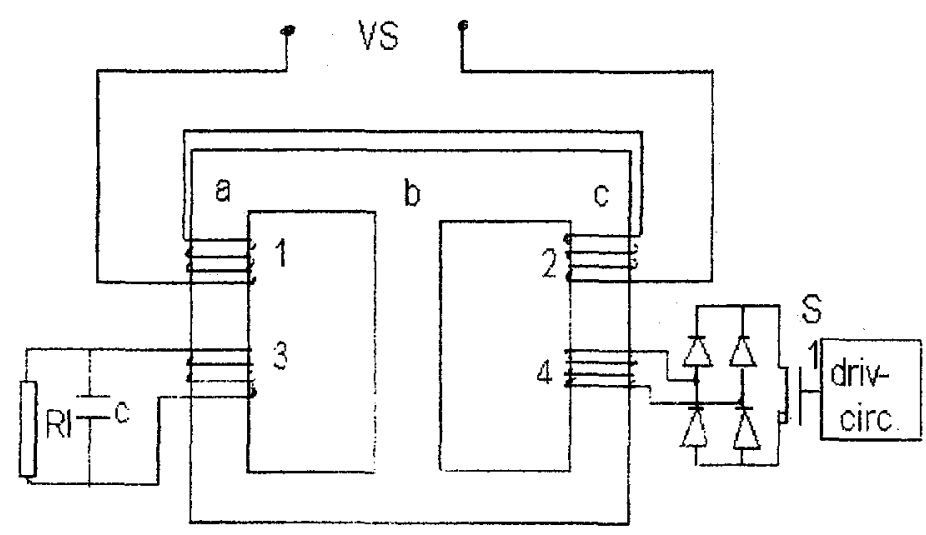

Fig.[1] The proposed system

Coil 4 , can be shorted via one MOSFET controlled with trigger circuit according to PWM technique. Coil 3, is connected to the load and is shunted by a capacitor, to improve the load voltage waveform.

The mechanism of load voltage regulation is based on flux division between the two outer limbs, which is affected by the MOSFET operation modes. If the switch $S_{1}$ is off, the supply voltage applied to coils 1 and 2 will produce flux $a \mathrm{~b}$ will be equal to the sum of fluxes in outer limbs and $\phi$, The 
supply voltage is shared between the coils 3 (load) and coil 4 (switch). Also, the voltage at the load terminals will depend on the equivalent impedance of the load and the capacitance.

When switch $S_{1}$ is on, the change in the total flux due to the supply voltage will flow in the limb a, as the flux in limb c will be nearly frozen. Hence, the load and capacitor voltages become nearly equal to the supply voltage. When the switch $S_{1}$ is turned off most of the change in the total flux produced from the supply will flow in the limb $\mathrm{c}$ due to the effect of the load and capacitor equivalent impedance. During this period the capacitor will be discharged into the load. The load voltage and the supply current waveforms are affected by the capacitor value.

\section{4-Equivalent circuit and analysis:}

Considering Fig.[1], and the flux distribution in the magnetic circuit, an equivalent circuit which represents the system can be proposed as shown in Fig.[2]. The two outer limbs core can be represented by two equal impedance's $Z_{\mathrm{a}}$ and $Z_{\mathrm{c}}$, that represents the magnetizing components and iron loss components. Also, the core of the center limb can be represented by $Z_{b}$. The flux in the center limb equals the flux in the two outer limbs, so $Z_{a}$ and $Z_{c}$ are connected in parallel with $Z_{b}$. However, the effect of the coil resistance's, leakage inductance's, switch and load impedance can be represented as shown in Fig.[2]. The equivalent circuit parameters can be measured using the conventional short and open circuit tests. The system parameters are listed in the appendix.

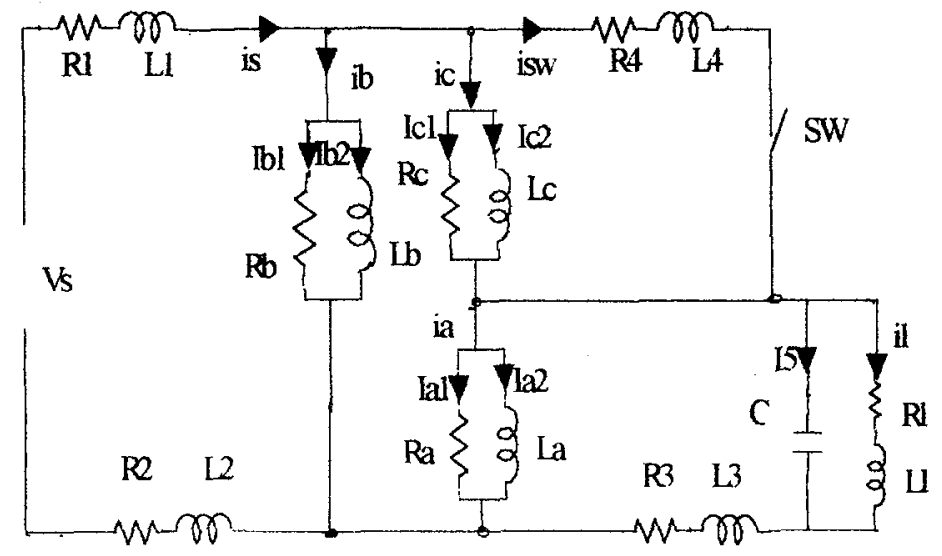

Fig.(2) The proposed system equivalent circuit

From the equivalent circuit. the system equations are :

$$
\text { 1. } E_{h}=i_{s}\left(R_{1}+R_{2}\right)+\left(I_{1}-I_{1}\right) \frac{d i_{2}}{d t}
$$

and

$$
E_{h}=i_{b 1} R_{b}=I_{h} \frac{d i_{b:}}{d t}
$$

Where:

$$
i_{h}=i_{b 1}+i_{b 2}
$$

In the outer limbs, the EMF's depend on the flux distribution. When switch $S_{1}$ is open, a higher part of the flux produced from the supply will flow in the limb 
c, and the minimum part will flow in the limb a, this depend on the equivalent impedance of the load and capacitance. As the equivalent impedance of the load and capacitance is increased the flux in limb a is decreased: When switch $S_{1}$ is on, the flux in limb c will be minimum, and nearly all the flux produced from the supply voltage will flow in limb a. In general case:

$$
E_{b}=E_{a}+E_{c}
$$

Where:

$$
E_{a}=i_{a 1} \cdot R_{a}=L_{a} \cdot \frac{d i_{a 2}}{d t}
$$

and

$$
E_{c}=i_{c 1}, R_{c}=L_{c} \cdot \frac{d i_{c 2}}{d t}
$$

The magnetizing currents in these limb's are given as follows:

$$
\begin{aligned}
& i_{a}=i_{a 1}+i_{a 2} \\
& i_{c}=i_{c 1}+i_{c 2}
\end{aligned}
$$

In $\operatorname{limb} a$, the voltage applied to the load and capacitor can be calculated from the following equation:

$$
E_{a}-V_{l}=\left(i_{5}+i_{1}\right) R_{3}+L_{3} \cdot \frac{d\left(i_{5}+i_{l}\right)}{d t}
$$

Where $i_{5}$ is the capacitor current, the capacitor voltage will equal to the load voltage so;

$i_{5}=c \cdot \frac{d v_{c}}{d t}=c \frac{d v_{1}}{d t}$

and

$$
V_{l}=R_{l} i_{l}+L_{l} \cdot \frac{d i_{l}}{d t}
$$

The supply current, load voltage and current depend on the switch $S_{1}$ operation. When switch $S_{1}$ is on, the supply current is

$$
i_{s}=i_{b}+i_{c}+i_{s w}
$$

where $I_{\text {sw }}$ is the switch current.

In this case the voltage at coil 4 terminals is given by:

$E_{c}=i_{s w} \cdot R_{4}+L_{4} \frac{d i_{s w}}{d t}$

As switch $\mathrm{S}_{1}$ is off,

$i_{s h^{\prime}}=0.0$

and the supply current is :

$i_{s}=i_{h}+i_{a}+i_{5}+i_{l}$

The differential equation describing the different modes of operation of the system are solved using simulink program with fourth order Rung-Kutta method. Calculations are carried out assuming zero initial conditions of magnetic circuit flux. Also, there is no saturation in the magnetic circuit.

\section{5-Simulation and experimental results:}


The experimental results is carried out to verify the feasibility and to investigate the validity of the computed results for the PWM technique of magnetic circuit flux control. Fig. [3-a-b] shows the supply current waveform at switching frequency of $1000 \mathrm{~Hz}$. Fig. [4-a-b] shows the load current at the same conditions. Fig.[5-a-b] shows the capacitor current. It is observed that the experimental waveforms are in good agteement with the computed waveforms. Also, it is noticed that during off period of the switch, the capacitor discharge in the load to improve the load current waveforms, thus it will effect in the supply current waveform.

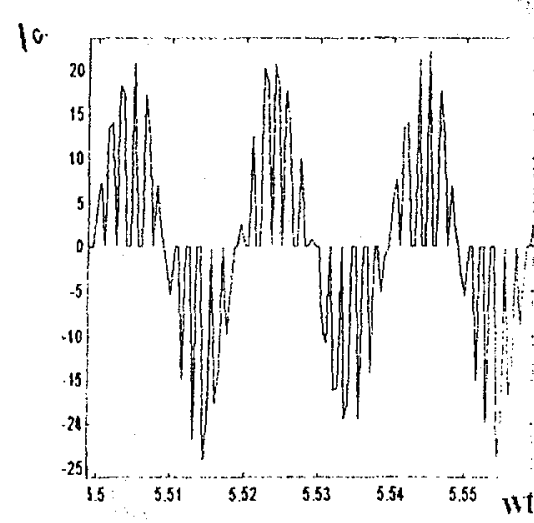

a- simulation waveform

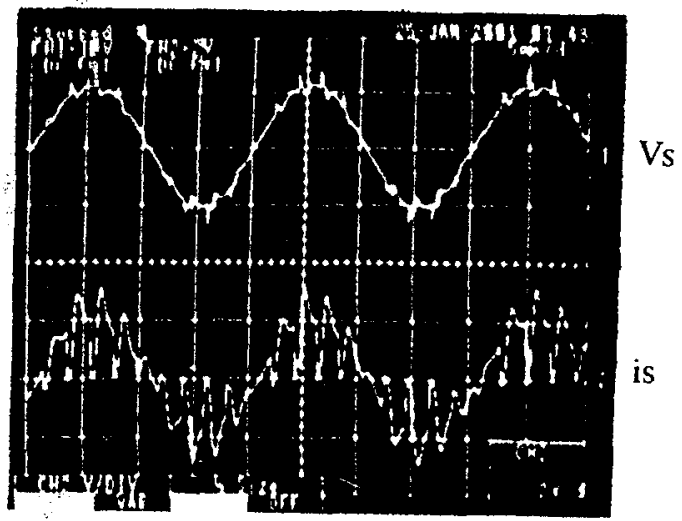

Ch2 is $2 \mathrm{amp} / \mathrm{div}, \mathrm{t}=5 \mathrm{msec} / \mathrm{div}$ b- Experimental waveform

Fig.[3] The supply current waveform at a switching frequency of $1000 \mathrm{~Hz}$

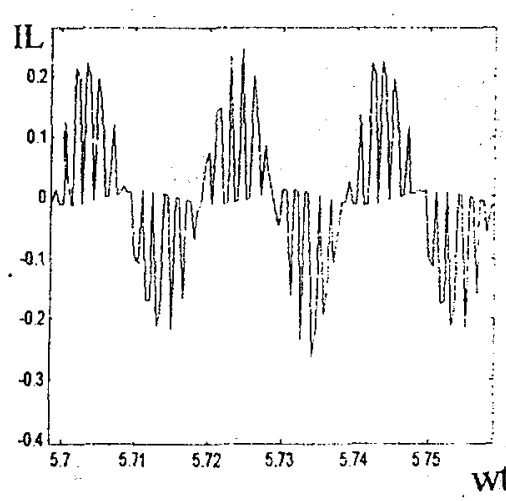

a- Simulation waveform

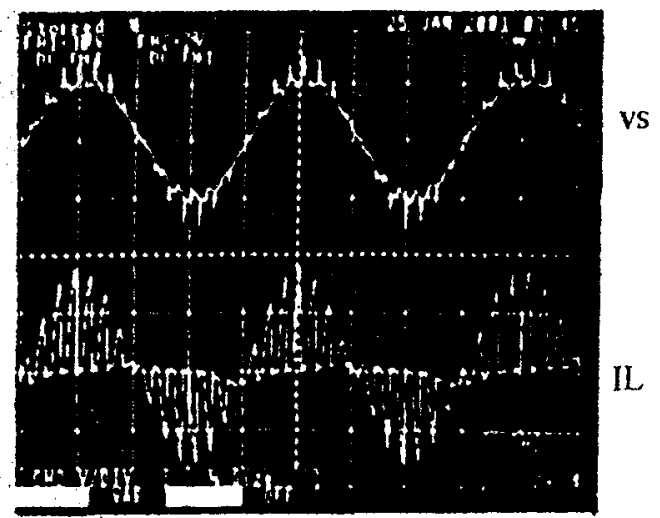

$\mathrm{Ch} 2$ is $0.2 \mathrm{amp} / \mathrm{div}, \mathrm{t}=5 \mathrm{msec} / \mathrm{div}$ b- Experimental waveform

Fig. [4] The load current waveform at a switching frequency of $1000 \mathrm{~Hz}$

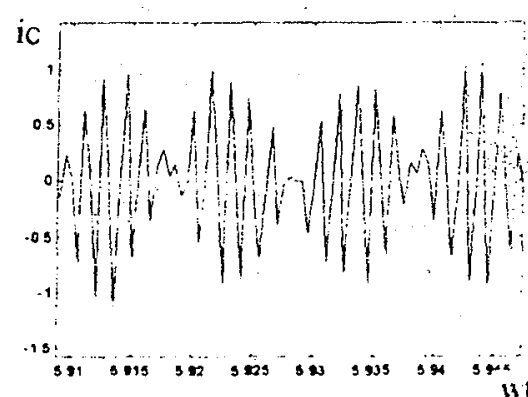

a- Simulation waveform

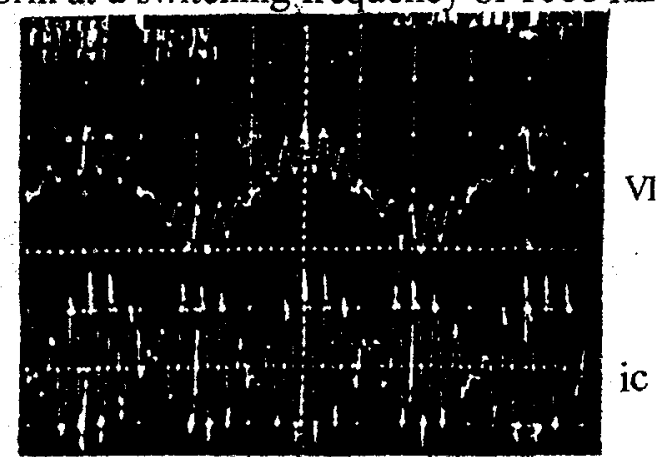

Ch2 is lamp/div, $t=5 \mathrm{msec} / \mathrm{div}$

b- Experimental waveform

Fig [5]The capacitor curtent waveform at a switching frequency of $1000 \mathrm{~Hz}$ 
Figs:[6-7-8] shows the supply current, load current and capacitor current at switching frequency equals to $2500 \mathrm{~Hz}$. The result shows that as the switching frequency increases the inductance of the coils will increase, thus, decreases the load voltage. Hence, the capacitor value must increases to increase the load voltage to the maximum load voltage.

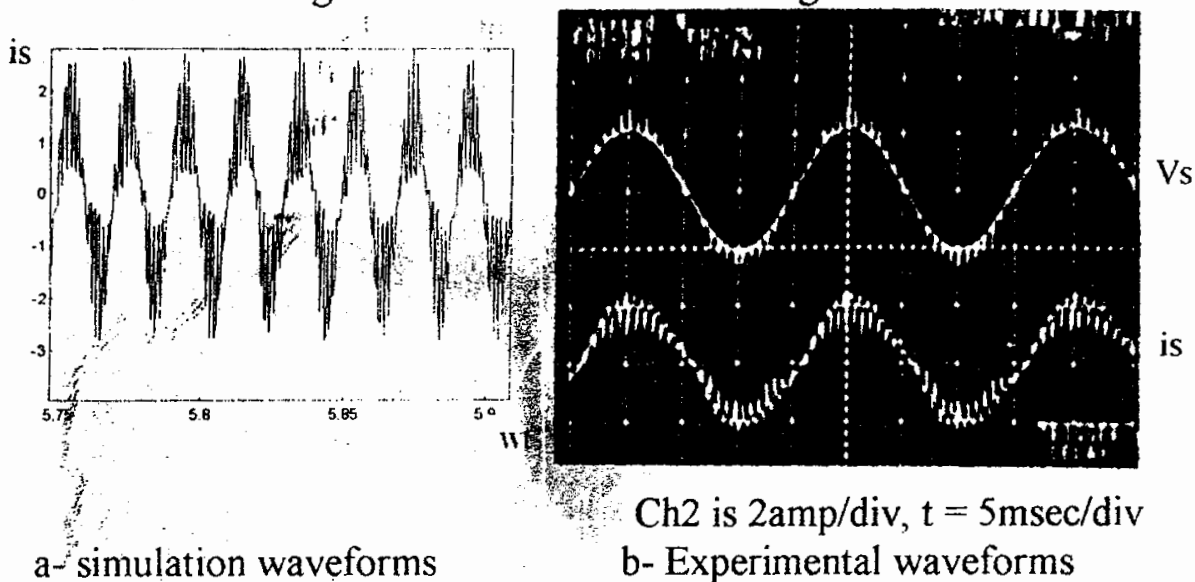

Fig.[6] The supply current waveforms at switching frequency $2500 \mathrm{~Hz}, \mathrm{c}=50 \mu \mathrm{f}$

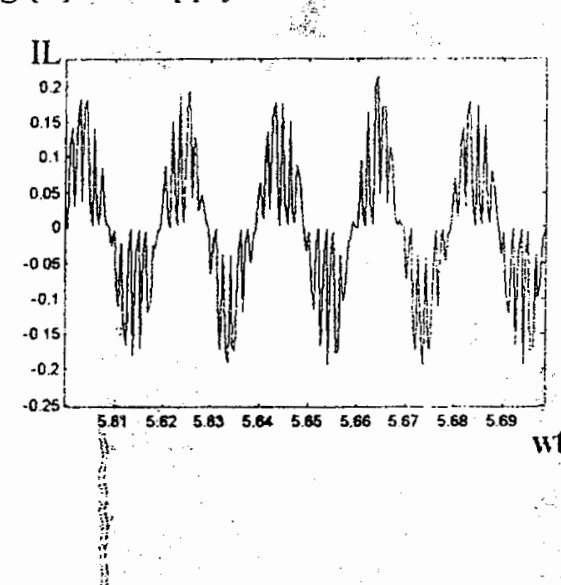

a- Sinulation waveforms

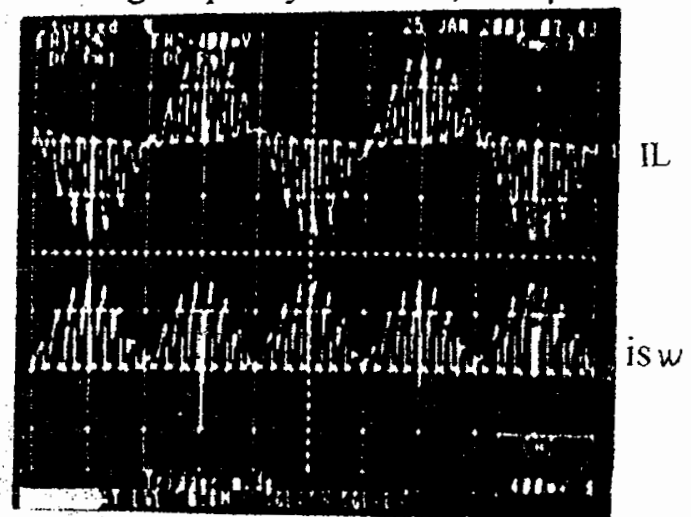

Chi is $0.2 \mathrm{amp} / \mathrm{div}, \mathrm{t}=5 \mathrm{msec} / \mathrm{div}$ b- Experimental waveforms

Fig.[7]The load current waveforms at switching frequency $2500 \mathrm{~Hz}, \mathrm{C}=50 \mu \mathrm{f}$

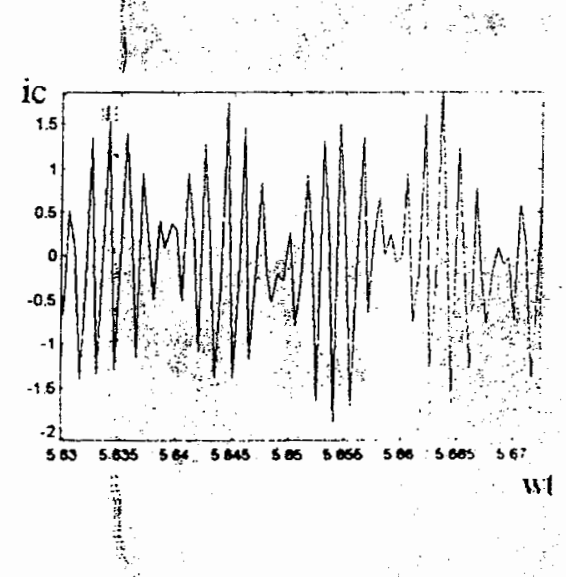

a- theoretical waveforms

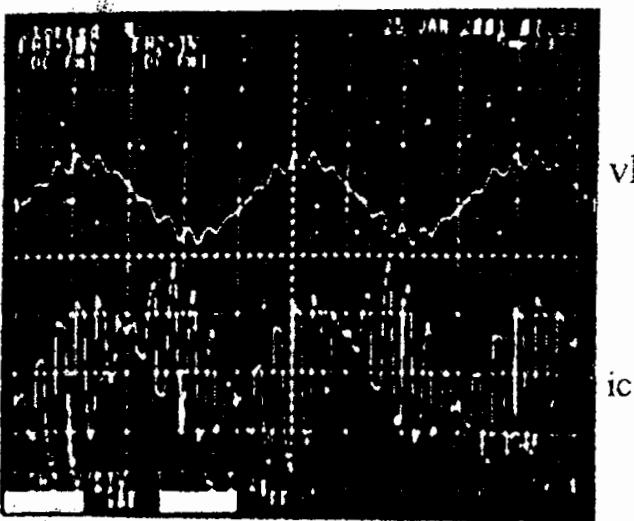

Ch2 is lamp/div, $\mathrm{t}=5 \mathrm{msec} / \mathrm{div}$ b- experimental waveforms

Fig.[8] capacitor current waveforms at switching frequency $2500 \mathrm{~Hz}, \mathrm{C}=50 \mu \mathrm{f}$ 
The harmonic analysis of the supply current and load current are carried out. Also, the power factor at the supply terminals is obtained. Fig. [9] shows the supply current harmonic spectrum at switching frequency $1000 \mathrm{~Hz}$ with capacitor value equal to $50 \mu \mathrm{f}$. Fig.[10] shows the variation of the power factor at the supply terminals as function of the switching frequency at different values of capacitance $(25,30,50 \mu \mathrm{f})$. It is noticed that as the capacitor value increase the power factor at the supply will increased. Also, the power factor decreased as the switching frequency increased.
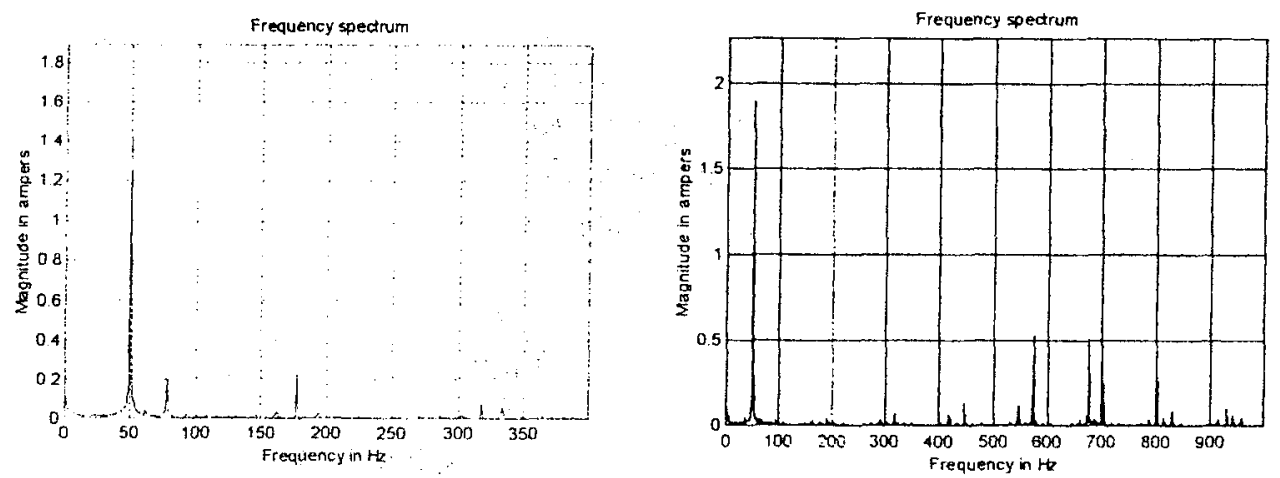

a- at switching frequency $500 \mathrm{~Hz} \quad$ b- at switching frequency $1000 \mathrm{~Hz}$ Fig.[9] The supply current harmonic spectrum ( $c=50 \mu \mathrm{f}$ )

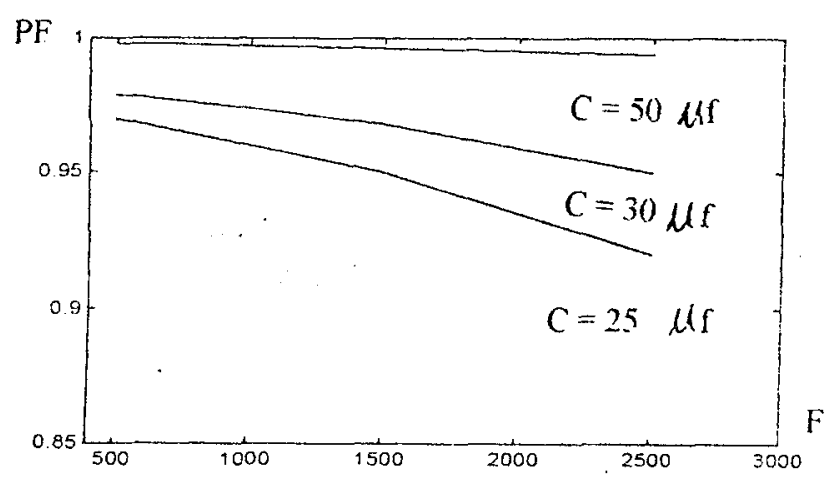

Fig.(10) Computed power factor at the supply terminals

\section{6-Conclusion:}

The ac voltage regulator for resistive loads using PWM technique proposed in this paper avoids the main demerits of moving coil voltage regulator such as the mechanical system. Also, it avoids the poor power factor at the supply terminals of the conventional thyristor voltage regulators. The proposed regulator gives smooth variation of the load voltage as the duty cycle of MOSFET operation is varied. Also, it gives sinusoidal supply current and improvement power factor at the supply terminals that in range 0.92 to 0.989 .

The suitable value of capacitance at the load terminals gives improvement in the power factor and the supply current waveforms. Equivalent circuit of the proposed regulator has been obtained and justified by comparing the computed and experimental results that are in good agreement.

\section{7-appendix:}

Parameters of the experimental set up given as follows: 


$$
\begin{aligned}
R_{1} & =2.0 \mathrm{ohm}, R_{2}=2.0 \mathrm{ohm}, R_{3}=2.0 \mathrm{ohm}, R_{4}=2.0 \mathrm{ohm}, \\
L_{1} & =0.2 \mathrm{mH}, \mathrm{L}_{2}=0.2 \mathrm{mH}, \mathrm{L}_{3}=0.2 \mathrm{mH}, \mathrm{L}_{4}=0.2 \mathrm{mH}, \\
R_{\mathrm{a}} & =730 \mathrm{ohm}, \mathrm{R}_{\mathrm{b}}=1085 \mathrm{ohm}, \mathrm{R}_{\mathrm{c}}=730 \mathrm{ohm}, \\
\mathrm{L}_{\mathrm{a}} & =13.7 \mathrm{mH}, \mathrm{L}_{\mathrm{b}}=28.0 \mathrm{mH}, \mathrm{L}_{\mathrm{c}}=13.7 \mathrm{mH}, \\
\mathrm{R}_{1} & =50.0 \mathrm{ohm} .
\end{aligned}
$$

\section{Reference:}

1-J. Arrillage, B. Barrett and N.A.Vovos" Thyristor-Controlled Regulating Transformer For Variable Voltage Boosting," Proc.IEE, Vol.123, No. 10, October 1976, PP. 1005-1009.

2-G.H. Rawcliff and I.R.Smith, "The Moving-Coil Voltage Regulator: A treatmenent From first Principles," Proc. IEE. 104A, 1957, PP 68-76

3-A.S. Abdel-Karim," The Moving-Coil Regulator. A Simplified Treatment," Electric Machines and Power Systems, Vol. 8, No.4, 1983, PP 395-402.

4-C.F.Amor," Electrical regulators," Patent Specification, No. 1353012, Patent Office, London, May 1974.

5-A.S.Abdel-Karim, A.S.Taalab and A.E.Lashine," A Thyristorized AC Voltage Controller With Sinusoidal Output," Proc. Electric Machines and Power Systems, Vol.16, 1989, PP.395-410.

6-A.S.Abdel-Karim, S.A.Mahmoud and A.El-Sabbe," A New Approach TO Capacitor Compensation of Thyristor Voltage Controller," UPEC, 1985.

7- Do-hyun Jang and Gyu-ha Choe,"improvement of input power factor in ac choppers using Asymmetrical PWM technique", IEEE. Trans. Ind. Elect. Vol.24, No. 2, april 1995, pp. 179-185.

9- G.Choe and D Jang." Asymmetrical PWM technique for ac choppers", in IEEE. IECON conf. 1991, pp 587-594.

10- A.El-Sabbe and A. Zin El-Din, "A Novel ac voltage regulator, "IEEE. IECON conf. 1998. Germany, pp. 607-611.

11- Yim-Shu Lee, K.C.Wong and C.K.Ng," Behavior Modeling of Magnetizing Currents in Switch-Mode DC-DC Converters," IEEE. Tran. Ind. Elect. Vol. 47, No. 1, Feberuary 2000, pp. 36-44. 
حاكم جهد ذو موجة خرج جيبية بأسلوب التحكم بالنبضات متغيرة الاتساع

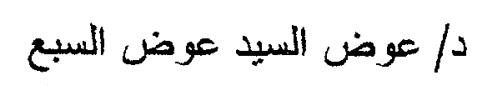

قسم الهندسة الكهربية - كلية الهندسة بشبين الكوم - جامعة المنوفية

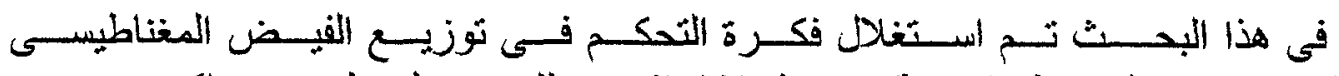

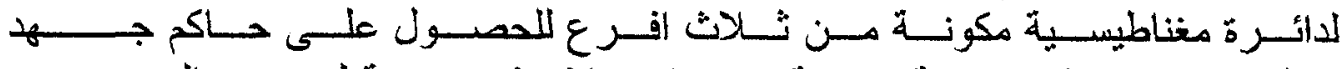

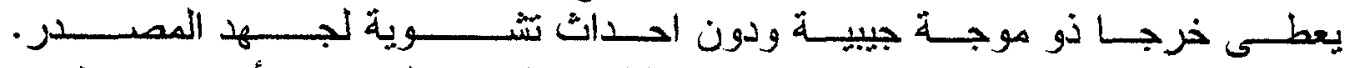

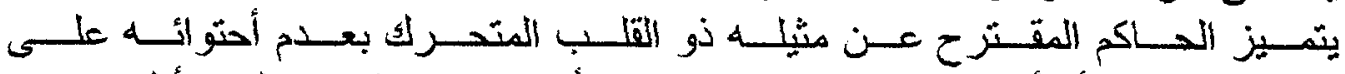

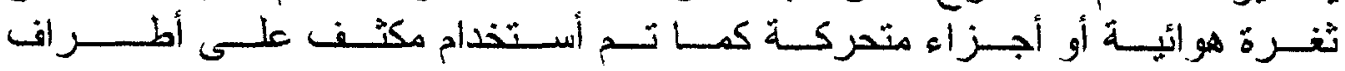

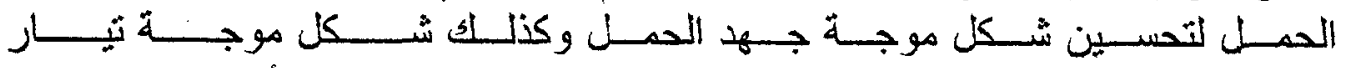

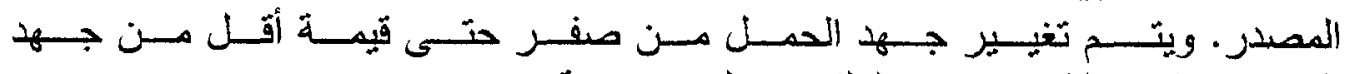

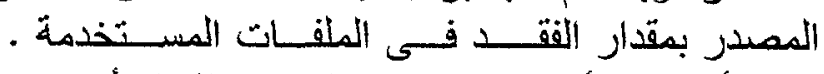

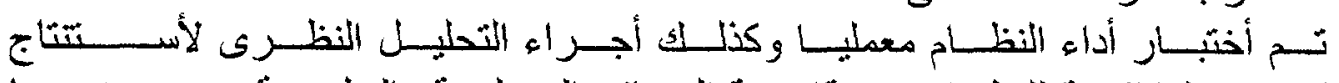

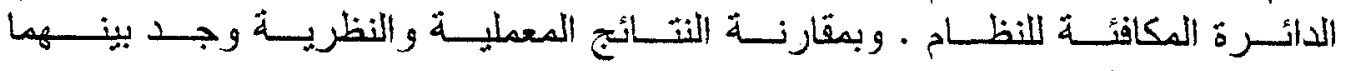

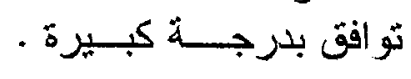

